\title{
Paisajes Culturales de Cobija, Costa de Antofagasta, Chile.
}

\section{Cultural Landscapes from Cobija, Coast of Antofagasta, Chile.}

\author{
Victoria Castro', Carlos Aldunate ${ }^{\text {II }}$ Y Varinia Varela ${ }^{\mathrm{II}}$
}

\begin{abstract}
RESUMEN
Hoy se advierten diferentes percepciones sobre el territorio del Norte Grande de Chile; algunas pertenecen a los descendientes de los pueblos originarios de tiempos prehispánicos, otras, corresponden a la narrativa de la gente que escribe sobre el territorio a partir del siglo XVI, especialmente los extranjeros que lo ocuparon, y también está la percepción de los mestizos del presente. Unos han construido una vida de esfuerzo y bienestar; los otros se preguntan quién puede vivir en semejante desolación. Se está en definitiva, ante formas de percibir este paisaje muy diferentes y prácticamente irreconciliables. No obstante, tanto el registro arqueológico como el relato histórico, hacen notar que este territorio, a pesar de ser aparentemente casi inhabitable por su extrema aridez, ha sido integramente aprovechado por los habitantes locales desde sus primeros poblamientos. Sobre estas contradictorias bases, nos interesa situar nuestra narración. Nos centraremos en los paisajes del desierto costero, que los especialistas hemos acordado llamar así, como herramienta de trabajo, por costumbre histórica, narrativa arqueológica, una visión lejana de un desierto supuestamente intocado y el mar Pacifico.
\end{abstract}

Palabras clave: Paisajes Culturales, Costa Desértica, Atacama

\section{Abstract}

This paper deals with the different perceptions of Chilean northern landscapes that are commonly refered to as the Atacama Desert. The present aboriginal descendants of the peoples that inhabited these lands throughout millennia conceive and live in this part of the country in different ways as the europeans that first explored these territories, and the modern immigrants, today engaged in the extractive industrial activities that

\footnotetext{
Investigadora Asociada Museo Chileno de Arte Precolombino. Universidad Alberto Hurtado. Las Perdices 575, La Reina, Santiago. Correo-e: vcastror53@gmail.com

ii Museo de Arte Precolombino, Bandera 361, Casilla 3657, Santiago. Correo-e: caldunate@museoprecolombino.cl; vvarela@museoprecolombino.cl

iii Museo de Arte Precolombino, Bandera 361, Casilla 3657, Santiago. Correo-e: caldunate@museoprecolombino.cl; vvarela@museoprecolombino.cl

Recibido: octubre 2010. Revisado: agosto 2011. Aceptado: mayo 2012.
} 
are making the northern cities grow faster than ever. We are interested especially in the local peoples that had and have taken the best advantage of the poor natural resources in this territory. In this occasion, we will focus our interest on the coastal territories of Antofagasta Region, characterized by its extreme dryness, with no permanent sources of fresh water, in contrast with a great richness of its maritime resources.

Key Words: Cultural landscapes, Desertic coast, Atacama.

\section{INTRODUCCIÓN}

El "desierto costero" es un término amplio, que todavía se percibe homogéneo por la falta de estudios arqueológicos sistemáticos y continuos que le otorguen sentido y especificidad a los componentes poblacionales que allí han habitado, transitado y asentado de un modo u otro desde los tiempos prehispánicos. Esta costa aparenta ser, a primera vista, ajena al paisaje de oasis, valle o quebrada de las tierras interiores, y desde el punto de vista arqueológico se asemeja a una sombra frente a referentes documentados por la etnohistoria, para una de las localidades que concita nuestro interés, cual es el caso de Cobija. Esta localidad queda comprendida en el espacio de la costa desértica de interfluvio, un territorio con la apariencia de un desolado desierto, en donde la vida no es posible sino a expensas de escasas y escuálidas aguadas salobres y de mala calidad.

Es para este espacio que queremos dar a conocer las diferentes percepciones del paisaje a través de registros arqueológicos, etnohistóricos y etnográficos que documentan distintos paisajes culturales que cruzan el tiempo en estos territorios. En el presente, la antropología trata de superar la ruptura entre naturaleza y cultura tratando de integrarlas, considerando que la cultura se genera en su relación con la naturaleza y ésta a su vez es modificada por la cultura; así el paisaje es el lugar de la lectura de la historia pues surge de la experiencia del ser humano (Devora 2006). Asumimos la noción de que un paisaje cultural es una construcción social que se impregna de la experiencia cotidiana.

Dicho de otro modo, la lectura del paisaje es completa cuando a las características físicas y biológicas del sistema paisajístico se añaden aquellas antrópicas y culturales. De hecho, la visión de conjunto no deriva de una simple suma de las partes, sino que nace de las relaciones entre las partes (Castiglioni 2007), o como indica Ingold (1996: 23), "las acciones humanas están incorporadas al ambiente". En este contexto podemos afirmar que existen una serie de paisajes culturales que se han desarrollado en la localidad de Cobija, los que se organizan como verdaderos "Estados de sistema" (De 
Saussure 1945:11). Es por ello que la presentación sigue un hilo histórico temporal, no obstante que varios paisajes se entretejen en el tiempo. Uno de los más persistentes es el "paisaje chango", articulado por un quehacer cotidiano vinculado a la recolección, pesca y caza de recursos marinos.

La investigación se sitúa en el norte de Chile, sector costero del Desierto de Atacama, entre las actuales ciudades de Tocopilla y Mejillones, uno de los lugares más desérticos del mundo (Fig. 1). Hoy, este paisaje está urbanizado por una carretera costera, que ha seccionado asentamientos de diferentes épocas, funciones y categorías. Los más evidentes y contrastantes con el paisaje son aquellos pertenecientes a la minería industrial, en el faldeo de los cerros de la cordillera de la costa, que en ocasiones llegan hasta el mar. Estas instalaciones conviven con los asentamientos de pescadores, cuyas rancherías demuestran que el modo tradicional del uso de este paisaje continúa de forma similar a las primeras ocupaciones humanas de este sector.

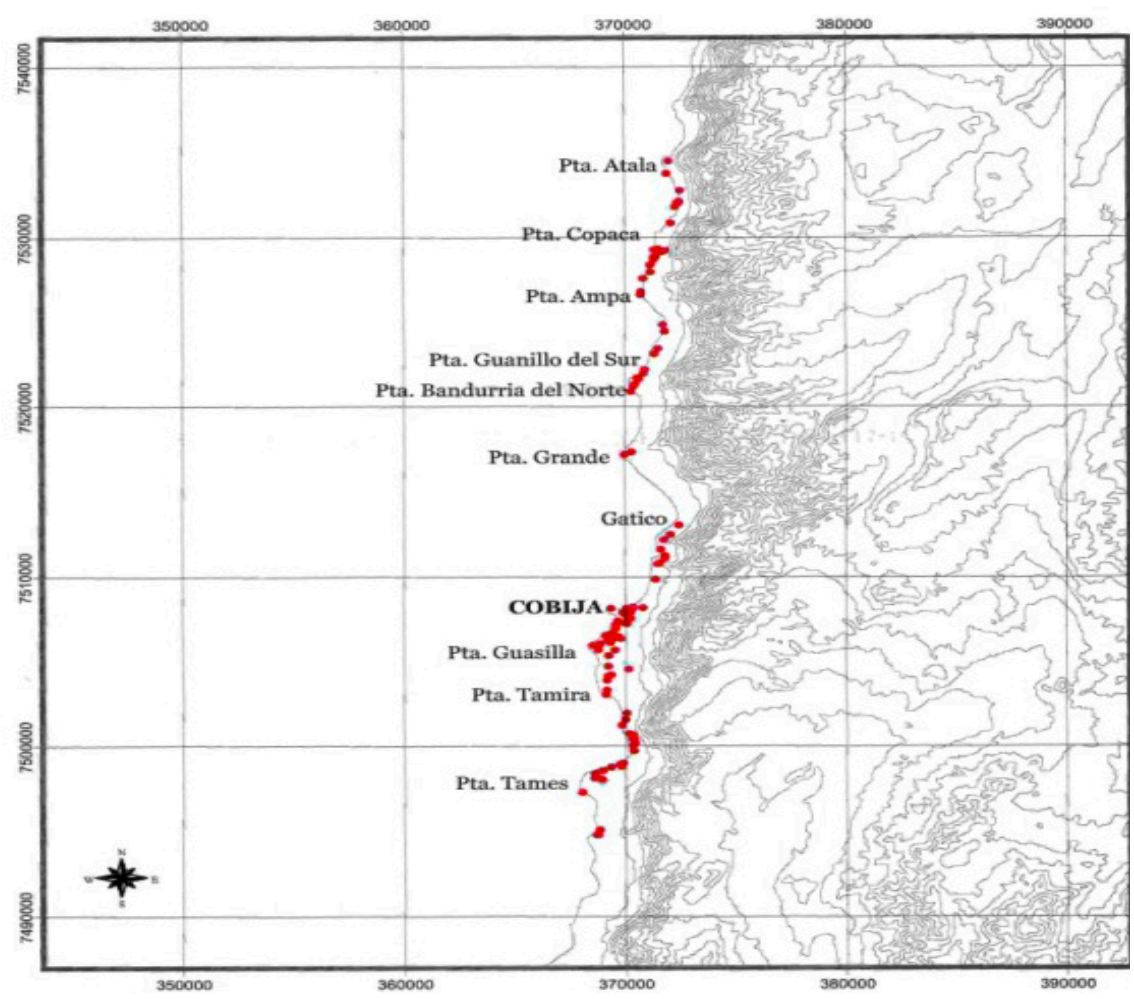

Figura 1: Mapa del área de estudio. Puntos corresponden a sitios arqueológicos Figure 1: Map of the study area. points are archaeological sites. 
En el pasado prehispánico, la costa desértica de interfluvio recibió a poblaciones que usufructuaron de las escasas y salobres aguadas de la zona, dentro de un amplio patrón de movilidad litoral, cuya función era el máximo aprovechamiento de los extraordinarios recursos alimenticios que provee esta parte del litoral del Pacífico (Bittmann 1986). Posteriormente, en el primer milenio de nuestra era, la abundancia de estos recursos atrajo el interés de sociedades que vivían en los oasis y quebradas del interior, provocando movimientos poblacionales en la gradiente altitudinal (Aldunate et al. 2010).

Durante el S. XVII, la costa de Atacama, y en especial la localidad de Cobija, surge como un centro marginal para los intereses de la Corona Española, por su población originaria de pescadores, sus abundantes recursos marinos, y por ser el vínculo con el tráfico de ultramar en la famosa ruta de Potosí. Cobija también es un puerto alternativo frecuentado por corsarios, piratas y contrabandistas que burlan los intereses comerciales de la Corona a través de esta localidad que, debido a su lejanía, dificultad de acceso y escasez de agua, no está controlada por las autoridades administrativas (Bittmann 1980).

En los primeros años del S. XIX, la naciente república de Bolivia hace ingentes esfuerzos por desarrollar Cobija, por ser su única salida marítima y contacto con el comercio del exterior. A mediados del S. XIX, este puerto recibe a una población de unas 3.000 personas. Una serie de desastres naturales, pestes y una guerra terminan con estas intenciones y Cobija es abandonada; sus casas y el puerto desmantelado (Cajías 1975).

Pese a sus dificultades, este sector fue ocupado desde milenios por pescadores que desarrollaron una cultura especializada en la explotación de recursos marítimos. Aunque situaciones de carácter económicos y políticos tratan de ocupar este paisaje para otras funciones, ellas fueron derrotadas por las dificultades y desafíos propios del lugar.

En síntesis y a través del tiempo, pueden distinguirse en el desierto costero de Antofagasta una serie de paisajes culturales desde los poblamientos iniciales de la costa. Estos se transforman cuando se acentúa en los primeros siglos de la era cristiana el nexo costa - tierras altas y surgen conexiones algo estables con poblaciones andinas del interior. Posteriormente, con la invasión europea, hay percepciones exóticas de aprovechamiento económico de estos territorios que permanecen hasta períodos republicanos.

Desde el punto de vista geomorfológico, la zona se identifica por la existencia de pequeńas planicies litorales y la escarpada cordillera de la costa, 
entre un desierto absoluto y el mar Pacífico. El desierto está marcado por una aridez total y es considerado como el más seco del mundo, con un índice de pluviosidad promedio de entre 1 y $2 \mathrm{~mm}$ anuales. Aun así, existen escasas y pequeñas aguadas muy salobres y mineralizadas, de mala calidad para la vida humana, provenientes de napas que filtran por las costras salinas y minerales del desierto. Se caracteriza también por un arreísmo absoluto; en consecuencia las plantas son escasas aunque viven cactáceas y pastos estacionales en las cotas altas de la cordillera de la costa, alimentados por la neblina mojadora conocida como "camanchaca". En la planicie litoral predominan varias especies de la familia de las Nolanáceas y en la cordillera de la costa adyacente destacan especies arbustivas como Ephedra breana, gramíneas y las cactáceas Eulychnia iquiquensis y Cumulopuntia (Maldonado 2006).

De acuerdo a nuestros resultados, las poblaciones costeras de este litoral tuvieron acceso a la pesca de especies de mar abierto, como grandes atunes (Thunus sp.) y dorados (Coryphaena sp.), albacoras (Xiphias gladius) y delfínidos; peces semiabisales como los congrios (Genypterus chilensis y G. maculatus) (Llagostera 1982) y otros como cabrilla (Sebastes capensis) y pejeperro (Semicossyphus maculatus) (Ruz 2011). En especial se consumieron peces que habitan en ambientes rocosos. Las especies Cheilodactylus variegatus (bilagai, pez de roca), Sicyases sanguineus (pejesapo o chalaco), Semicossyphus maculatus (pejeperro), y la familia Labrisomidae (trambollos), son taxas características de los ambientes submareal e intermareal de la costa rocosa del norte de Chile (Torres 2008). También se dispuso de las taxas Paralichthys microps (lenguado) y Cilus Gilberti (corvina), que son especies que viven en ambientes litorales de aguas someras. Este último taxón habita en áreas cercanas a la costa en sectores de rompientes y playas arenosas, encontrándose incluso en aguas estuarinas. Durante los períodos tardíos prehispánicos (900 al 1530 D.C. aprox.), se puede percibir un mayor énfasis en la pesca y procesamiento del taxón Trachurus symmetricus (jurel), en la costa de Cobija y caletas aledañas, región de Antofagasta. Esta especie se acerca estacionalmente a ambientes litorales de baja profundidad como ensenadas y roqueríos. La aproximación de cardúmenes de jurel se produce principalmente en los meses estivales (Torres 2008, Castro 2010:39).

En cuanto a los moluscos, el mar de estas costas es pródigo. Inicialmente se dispuso en abundancia de Choromytilus chorus, en las épocas más tempranas de caza recolección; el repertorio que lo acompaña es vasto: lapas -Fissurellidae de varias especies- y locos -Concholepas concholepasque aunque presentan una mayor dificultad de extracción, por su ubicación 
y por estar fuertemente adheridos a las rocas, son populares como alimento. Existe una gran variedad de invertebrados marinos típicos del intermareal y submareal, principalmente de hábitats y rocosos, como Tegula, Loxechinus Albus (picoroco) y varias especies de Chitonidae (Castro 2010). De los mamíferos, cetáceos y lobos marinos han tenido una presencia y uso persistente en estas costas a través del tiempo. Otro recurso de esta zona son los yacimientos de cobre que se explotan desde épocas prehispánicas hasta hoy.

\section{El paisaje DE LOS PESCADORES Y RECOLECTORES DEL MAR}

A pesar de de la escasez del recurso hídrico, el ser humano se asienta en este paisaje y lo aprovecha de modo óptimo desde hace 10.000 años bajo una modalidad de caza y recolección marina, con una movilidad norte - sur por el litoral; y se establece en asentamientos transitorios, con una percepción del paisaje que, con transformaciones, continúa hasta hoy.

Los inicios de las fases tempranas de ocupación en el litoral de Antofagasta datan cerca del 10.000 AP, asociados a peces locales extintos y en menor proporción a guanacos (Llagostera 1977), con una abundante ictiofauna que persiste hasta el presente.

En esta misma zona puede reconocerse una Segunda Fase Arcaica, con un rango de entre 9.500 a $9000 \mathrm{AP}$, asociado a los famosos litos "Huentelauquén", puntas de proyectil pedunculadas y un variado material lítico artefactual (Llagostera 1977).

En Cobija y alrededores, se han estudiado sitios más tardíos, con una cronología de entre 6000 al 3.000 AP, que se caracterizan por la presencia de anzuelos de concha, espinas de cactáceas y hueso, puntas de base convexa, cóncavas, rectas, dobles puntas y pedunculadas, arpones, anzuelos compuestos y anzuelos circulares. Hay estructuras de piedra que sirvieron tanto para habitaciones como para funciones funerarias (Cobija 13 y Cobija 1S, Punta Blanca y Punta Guasilla) (Bittmann 1980, Cruz y Bravo 1980, Munizaga 1980).

Nuestras investigaciones en Copaca, al norte de Cobija (2010-2011), nos han permitido datar un asentamiento de mariscadores y pescadores del Arcaico, con un rango de RC14 de 7010 +- 30 años AP (UGAM 9145) en la base de la ocupación (capa 9) y 4.540 +- 25 ańos AP (UGAM 8342) en la capa 2. Este asentamiento denota una eficiente actividad marina, existiendo la posibilidad de uso de embarcaciones para pesca mar afuera, tal como 
lo sugieren también los análisis bioarqueológicos (Andrade 2011, 2012). Se encuentran estratigráficamente dispuestos en las capas de base e intermedias, restos de Marlin (Makaira indica), que darían sentido a este aserto, junto a la presencia de delfínidos y otáridos usados tanto con fines alimenticios como ofrenda mortuoria. Destaca una industria en concha y hueso, especialmente de camélido, de acabado fino, con instrumental asociado a pesca y caza (Castro et al. 2011). Este asentamiento de Copaca testimonia una excelente muestra del habitar y vivir en este paisaje con actividades económicas basadas casi exclusivamente en recursos marinos.

En relación al uso de embarcaciones, Llagostera (1990) ha buscado indicadores directos para esta actividad, estudiando otolitos de congrio (Genypterus chilensis) provenientes del sitio Punta Blanca, cerca de Tocopilla, obteniendo fechas de 1720 +- 50 AP (230 d.C), definiendo el uso de embarcaciones con mucho mayor grado de certeza en los inicios de nuestra era. Sin profundizar en el tema de la antigüedad de esta práctica, concordamos en que estos artefactos dieron una inusitada movilidad "caletera" a los pueblos de la costa desértica, y en que, la invención de embarcaciones representa un importante punto de inflexión en la historia de los pueblos costeros, porque cambia la relación económica que éstos mantienen con su mar adyacente y les abre un nuevo espacio vital, ampliando el ámbito visual de su conciencia colectiva y el ámbito geográfico de su existencia histórica (Berenguer 2008: 31).

En el transcurso del Arcaico, surge una nueva forma de habitar este espacio costero. Se construyen estructuras habitacionales con pisos de argamasa que incluye cenizas de algas y arena compactados con agua de mar, bajo los cuales hay enterramientos humanos (Bittman 1984), de la misma manera que ha sido documentado en nuestros estudios del sitio de Copaca 1. Esta configuración construye un paisaje donde se unen viviendas y estructuras funerarias.

La amplia distribución de estos yacimientos a través de toda la costa, su cantidad y densidad demuestran que durante las últimas fases del Arcaico costero ya se había consolidado una exitosa adaptación que permitió la existencia de enclaves a lo largo de todo el litoral, con una especialización creciente hacia la obtención de recursos del mar. 


\section{Percepción formativa del paisaje costero de Atacama}

El sitio Guasilla 29 que hemos estudiado, documenta claramente un momento situado dentro del formativo caracterizado por enterratorios de túmulos con postaciones de cactáceas y esteras de fibra vegetal. Hemos datado estos sitios en un rango de RC14 : 1750 +- 25 AP; 140 +- 25 (UGAM 8350) a 1810 +- 25 AP (UGAM 9146). Este tipo de patrón funerario incorpora nuevas y ricas tecnologías en los ofertorios (esteras en abundancia, tejidos, adornos cefálicos, etc.). En el área de estudio ha sido documentado el sitio funerario Cobija 10, calificado por Moragas (1982) como la extensión más meridional de la tradición de túmulos descubierta en el lejano sitio de Alto Ramírez en Arica. Esta investigadora propone una cronología de 320 años a.C. y 350 años d.C. para estos túmulos de la costa arreica.

Estos sitios funerarios demuestran una diferencia ideológica respecto de los del Arcaico, pues aparecen enterratorios en densos cementerios de alta visibilidad que coexisten con los antiguos sitios de pescadores y recolectores marinos, en donde se habilitan sectores funerarios de carácter discreto asociados a las habitaciones, que no interrumpen el paisaje.

En esta época, también se habilitan caminos para el tránsito entre tierras altas y costa, como lo demuestran los estudios del sitio encontrado sobre una ruta que lo vinculan con otros pisos ecológicos localizados a unos $10 \mathrm{~km}$. de Tocopilla con el río Loa bajo y que podría continuar hasta el Loa Medio (Calama - ChiuChiu). Se trata de un contexto funerario único que comprende un montículo de piedras y sedimentos que contenía en su interior un individuo y su ofertorio: un textil cubría su tórax y abdomen y sobre él, cinco plumas pequeñas; también tenía una bolsa tejida cerca de la cara, con múltiples reparaciones, aspecto detectado para los tejidos costeros. Fechados absolutos sitúan al individuo en un rango de entre 780 a.C. a 240 d.C. (Cases et al. 2008). Dentro de las patologías reconocidas, el individuo presentaba exostosis auditiva reactiva de grado leve, una lesión frecuentemente asociada a individuos dedicados al buceo (Cases et al. 2008). Adicionalmente los autores constatan la asociación de 272 restos óseos de peces, provenientes tanto de la bolsa anillada, del contenido estomacal del individuo y del tamizado de sedimentos; aquellos identificados, corresponden a peces de hábitos de orilla (Cases et al. 2008: 63). Los investigadores plantean que el eje de tránsito fue utilizado por gente proveniente de la costa en este caso, y que el lugar del hallazgo señala un "área formalizada de descanso, siendo un paradero obligatorio para los viajeros interzonales” (Cases et al. 2008:67). 
Otra investigación sobre rutas interzonales (Pimentel et al. 2010), provee los resultados de excavaciones de dos paskanas o áreas de descanso en el sendero, destacando que el $74 \%$ de los restos óseos asociados corresponden a peces; también hay crustáceos y bivalvos. Los autores postulan que esta ruta debió ser usada entre los 800 a.C y los 300 d.C. Estos nuevos hallazgos amplían el paisaje y su percepción más allá del litoral, a lo largo de la transecta actitudinal.

De reciente aparición son las noticias sobre la aldea y cementerio de San Salvador, situada a unos $100 \mathrm{~km}$ de la costa hacia el interior (Torres et al. 2012), con una población que ha sido datada con fechas que la asocian al período Formativo Medio (410 - 360 cal. BC). Esta población estaría involucrada dentro de una movilidad costa - Tierras Altas, ampliando y diversificando notablemente su dieta.

\section{LOS PERIODOS TARDÍOS}

Entre el período Formativo y tiempos tardíos prehispánicos, percibimos una cultura marítima bien asentada, con tecnología especializada, saberes y quehaceres que nos permiten proponer que estamos frente a una época donde se percibe un extensivo uso de embarcaciones, que amplían notablemente el paisaje y dan acceso a nuevos recursos marinos y terrestres. Los pueblos del interior también se interesaron en el litoral para obtener pescado y posiblemente también algas y guano de aves de los islotes costeros, para abono de los campos de cultivo en oasis y quebradas.

Algunas especies de moluscos como el loco (Concholepas concholepas), no solo fueron apreciadas por su carne blanca; sus conchas se encuentran fuertemente asociadas a contextos del período Intermedio Tardío conteniendo pigmentos de minerales rojos (óxido de fierro), comúnmente usado para pintura rupestres. Mientras estos y otros productos viajaban al interior, la gente de la costa recibió alfarerías de buena calidad confeccionadas en las tierras altas de Tarapacá, los oasis de San Pedro de Atacama y el río Loa (Varela 2009), así como productos agrarios, ganaderos y de recolección vegetal.

En consecuencia, durante el período Intermedio Tardío, se amplía este paisaje en la medida que su integración con las tierras altas de los oasis de Atacama se intensifica. El hallazgo de algarrobo, chañar, maíz y quínoa en contextos prehispánicos tardíos de Cobija es, junto con la cerámica, indicativo del traslado de estos recursos que provinieron del interior. En la 
costa, el uso de embarcaciones permitió la caza y pesca a mar abierto, así como un desplazamiento mucho más rápido por el extenso litoral. La tecnología de embarcaciones está bien desarrollada ya hacia los 900 d.C., jugando un rol decisivo en el abastecimiento de diferentes recursos a nivel regional y facilitando intercambios latitudinales hacia el norte y el sur. En la quebrada del Médano, a cuarenta kilómetros al norte de Taltal, existen pictografías en colores rojos, que reproducen escenas de caza de cetáceos, arponeados desde balsas de cueros de lobo y caza terrestre con arqueros (Mostny y Niemeyer 1983, Núńez y Contreras 2008, Berenguer 2009, Niemeyer 2010). Estos paneles podrían ser considerados como una representación particular de los pescadores del paisaje marino (Berenguer en Niemeyer 2010). El tema de la complementariedad entre costa y tierras altas, queda demostrado en los términos que L. Núńez (1996) y J.L. Martínez (1996), han descrito. Se trata de estrategias complementarias simultáneas, que también se ejercen a nivel latitudinal, desde tiempos Formativos. Esta forma de habitar el lugar persistirá a través de los siglos. Los cambios principales que ocurrirán en su horizonte de desarrollo están marcados por la presencia de pobladores foráneos.

Respecto a los recursos marinos, durante los periodos tardíos prehispánicos (900 al 1530 d.C. aprox.), se accede a otras especies. Así por ejemplo, la riqueza taxonómica registrada en Cobija en la región de Antofagasta, contiene taxas que dan cuenta de la explotación del intermareal superior y medio de tipo rocoso, y también del inferior o submareal somero, ya que se registra Megabalanus psittacus (picoroco) (Lucero 2008). También se puede percibir un mayor énfasis en la pesca y procesamiento del taxón Trachurus symmetricus (jurel), en Cobija y caletas aledañas (Castro 2010, Torres 2008).

En tiempos tardíos prehispánicos, el Inka se interesa por estas localidades probablemente por sus recursos mineros. El dominio del Inka en estos territorios está referido en crónicas tempranas:

Tenia Chuchi Capac opresas y sujetas más de ciento y setenta leguas de norte a sur, o como el se nombraba Capac o Colla Capac, desde veinte leguas del Cuzco hasta los Chichas y todos los términos de Arequipa y la costa de la mar hacia Atacama y las montañas sobre los Musos (Sarmiento de Gamboa [1572] 1988, en Zanolli 2005:58).

De naturaleza diferente y aunque brevísima, la información que ofrece Santa Cruz Pachakuti ([1608] 1968: 300) es tremendamente significativa para nosotros, cuando cualifica a los camanchas pescadores de Atacama como "grandes hechiceros". 
Este dato merece ser trabajado de acuerdo a la pregunta de porqué son connotados, casi siempre, en estos términos los grupos marginales a las grandes etnias y que se dedican a prácticas de caza, pesca y recolección (en definitiva a lo no domesticado). En el mismo sentido, se designa como hechiceros a los chuquilas de Chucuito (Matienzo [1557] 1910:179).

No obstante estas apreciaciones, ignoramos la valoración que el Inka le otorga a estas tierras y que pueden ser múltiples: metales preciosos, semipreciosos y colores como la alcaparrosa, un óxido de fierro rojo altamente valorado en la prehistoria regional (ver Salazar et al. 2009), que fue empleado en la confección de pinturas para el arte rupestre. La producción de charquecillo de pescado probablemente se elevó en escala con fines de intercambio como conserva. También es posible que el paisaje haya incluido una dimensión ideológica diferente del océano Pacífico, relacionada con las representaciones incaicas de la "mamacocha".

Vinculados o no al Inka, pero en el tiempo de su expansión, se ha propuesto que grupos del interior habrían llegado a Cobija a explotar una mina de cobre en la localidad, de fácil acceso y explotación (Latcham 1938, Núñez 1984: 319). Es una época en que la importancia de los metales es superlativa, de acuerdo a los hallazgos en cementerios de la época. Asimismo, el tráfico de metales incluyó movimientos entre tierras altas y bajas; en estas jornadas se movían además, bienes alimenticios, de estatus, de uso doméstico y materias primas (véase Núñez 1984: 137 y ss).

En nuestras investigaciones en esta zona, hemos apreciado la presencia Inka en asentamientos y sitios funerarios, especialmente a través de restos cerámicos del período Tardío, provenientes de tierras altas del altiplano, San Pedro de Atacama y el río Loa. Los cementerios de esta época son comparativamente más grandes, nucleados y aparentemente con una población mayor a la de los períodos anteriores. El total saqueo de estos sitios nos ha permitido, sin embargo, hacer un magro salvataje de estos restos.

Sin duda es una época de mayor diversidad e interdigitación étnica que las precedentes, pero aún bajo la percepción de espacios en que coexiste la vieja tradición de caza, pesca y recolección marina, con nuevos aportes que presta una tradición andina.

En síntesis durante los períodos Intermedio y Tardío, se advierte una definitiva ampliación del paisaje a nivel regional. Para los pueblos del litoral se produce una transformación del paisaje mucho más allá de la costa. $\mathrm{Su}$ vinculación con pueblos del interior diversifica su dieta, enriquece su 
intercambio y transforma su percepción ideológica del paisaje. En el período Tardío, la costa es parte del Tawantinsuyu, un imperio que se extiende por toda el área andina, lo que sin duda alguna produjo consecuencias que también afectaron la percepción ideológica del paisaje de los pescadores recolectores locales.

\section{LAS PERCEPCIONES COLONIALES}

La primera descripción que tenemos de nuestra área de estudio está hecha por un funcionario colonial y se refiere precisamente a Cobija:

En la ensenada de Atacama, ques donde esta el puerto, hay cuatrocientos indios pescadores uros, que no son bautizados ni reducidos, ni sirven a nadie, aunque a los caciques de Atacama dan pescado en señal de reconocimiento. Es gente muy bruta, no siembran ni cogen y susténtanse de sólo pescado (Lozano de Machuca [1581] 1885: XXV).

No es el momento de discutir el término "uro", que menciona el cronista, pero sí es necesario recalcar la relación asimétrica que establece entre las tierras altas de Atacama y la costa en épocas coloniales muy tempranas, donde muy probablemente se mantenían las mismas instituciones precolombinas. En este contexto recordemos que Polo de Ondegardo ([1571] 1916:79-80) señalaba las dificultades que surgían en el Collao, al tratar de encomendar los indios de los valles costeros, porque pertenecían a cabeceras que estaban en la altiplanicie.

Podemos asumir que mientras persiste el paisaje cultural asociado al pasado por parte de los indígenas, ellos son testigos del arribo de gente muy diferente de aquella que antaño bajaba de tierras altas; es gente ajena y desconocida.

Cobija, (220 32”) fue fundada en 1587, con el nombre de Santa María Magdalena de Cobija, para servir de refugio a los marinos en un tramo de la costa particularmente inhóspito (Fifer 1976: 53). Fuera de escasas descripciones de este sector en crónicas hispánicas, el conquistador español no mira ni se asienta en estos territorios sino de manera esporádica. La escasez casi absoluta de agua, la lejanía y dificultades de acceso a las tierras pobladas del interior, no fueron aliciente para un establecimiento importante y definitivo. Esto ocurrió en toda la costa arreica del desierto.

Sin embargo de lo expuesto, para la iglesia y en menor medida los encomenderos, este territorio, a pesar de sus inconvenientes, tuvo algunos 
atractivos que justificaron asentarse de manera esporádica en estos difíciles territorios.

En términos generales, los pescadores que vivían a lo largo de la costa del Norte Grande de Chile llamaron la atención de los europeos fundamentalmente en tres aspectos: su condición de vida ("bárbaros", "gente bruta", "pobres" o "miserables" (Bittmann 1979: 329, 1983:147), su movilidad y el aprovechamiento integral del lobo marino, para la construcción de balsas, viviendas, vestimenta, recipientes, cordelería y alimentos. Las citas de cronistas abundan en la riqueza de recursos marinos de la zona, y en la habilidad y especialización de los pescadores para cazarlos (Bibar [1558] 1966:12). Sin embargo, lo que atrajo más su atención fueron las balsas de cuero de lobo, de las más originales invenciones náuticas del mundo precolombino (Lizárraga [1594.1608], 1987: 150, 148).

\section{Evangelizadores y encomenderos (s. XVII - XVIII).}

Los conquistadores aprovechan la abundancia de peces, mariscos y mamíferos marinos y la habilidad de los pescadores para hacer sus trueques y comercio. Para facilitar el tráfico de estos recursos hacia las tierras altas, se aprovechan elementos prehispánicos, tales como el sistema de rutas prehispánicas que existía desde el período Formativo y que se había consolidado en épocas del Intermedio Tardío y Tardío y la tecnología de la conservación del pescado, que se procesaba para conseguir el charquecillo (Bauver en Bittmann, 1984:104).

Porque en aquella costa se haze grandissima pesca de congrios, tollos, lisas, dorados, armados, vagres, pulpos y otros muchos géneros de pescados que salpresan, y del que lleuan grandes recuas de carneros a Potosí, Chuquisaca,Lipes, y a todas aquellas provincias de la tierra de arriba, porque es el trato principal de aquella tierra con que an enriquesido muchos (Vásquez de Espinoza [1630] 1948: 618).

El puerto del mar del Sur más cercano a ella la ciudad de la Plata del Pirú, es el de Cobija, donde hacen las grandes pesquerias de congrio, liza, tollo y otros géneros de que se sustenta de pescado esta provincia de los Charcas (...) a la ciudad de la Plata llegan productos como pescado; hay mucho de la mar, saldo que se trae frescal, para las cuaresmas y entre año, tollo, congrio, liza, sardina, garcielo, corvina y otros muchos (Pedro Ramírez de Águila en Bittmann 1983: 147). 
Es interesante constatar la influencia de la Iglesia en Cobija y el litoral para la evangelización de los camanchacas, para lo cual fue necesario entrenar a los curas en las lenguas de la costa, pues estos no hablaban las generales quechua y aymara (AGI Charcas 92: fs.17r. y 72v 78 v y 9v, en Castro 1997).

En la primera mitad del S. XVII se celebran las primeras misas en Cobija en la iglesia de Santa María Magdalena del Mar. Para esta época contamos con los testimonios entregados en la Probanza de Méritos de Francisco de Otal (Castro 1997), que contienen significativas referencias para el sector, puesto que Otal fue cura y vicario de Cobija, donde sirvió por más de 24 años. En toda esta Probanza, hay distinciones entre los indios atacamas y los camanchacas, a quienes invariablemente se les llama también "indios Pescadores", apelativo que indica claramente la utilización que las autoridades coloniales daban a los pueblos locales.

Los eclesiásticos de Cobija hacían tanto énfasis en la evangelización como en el comercio y tráfico de pescado a las tierras altas de Atacama, Chuquisaca y Potosí, para recibir prebendas de autoridades como el Obispo de Potosí, el que escribe al cura Otal agradeciendo sus envíos de pescado "fresco":

haciendo la estimaçion que deuo del rregalo del atun que trajo el yndio muy saçonado y a buen tiempo y es cossa lindissima y rregaladissima y si buessa merçed se hallare en disPussiçion de ymbiarme mas deste genero y de los demas pescados que suele ymbiar Por agosto Lo estimare y Pagare a los indios mas mientras mas cantidad trajeren y si desto pudiere benir frescas como el otro y en preza entera Lo estimare con estremo aunque en la salmuera esta admirable (Castro 1997: A- 62 AGI Charcas 92: f 90 r)

Posteriormente, Otal obtiene aprobación para que se le asignen seis “indios camanchacas pescadores continuos" quienes deberán entregarle todo lo que pescan, a cambio de un pago que servirá a estos pescadores para enterar lo que deben al encomendero (Castro 1997: A-50; A-51. AGI Charcas 92: $f$ $72 \mathrm{r}, 72 \mathrm{v}$ y 74r). Ponemos énfasis en esta nueva categoría que demuestra la nueva situación de dominación, tan diferente a la andina, que tuvieron que afrontar los pueblos de esta costa.

En síntesis, el modo de vida tradicional indígena basado en la caza y recolección persiste, así como la relación y dependencia con las tierras altas, esta vez configurada en los nuevos términos establecidos por la colonia. Sin embargo, hay alteraciones fundamentales introducidas por el establecimiento 
del enclave colonial, aunque precario, en sus territorios, la evangelización, el tributo al encomendero y las relaciones sociales y económicas con los españoles. De más está señalar que la presencia europea fue una ruptura del paisaje de la época, de profundo impacto a nivel ideológico sobre las costumbres indígenas por el peso de la evangelización. Este sistema indígena coexiste con la construcción social ibérica para este lugar, fundamentalmente eclesiástica, que tiene que ver tanto con evangelizar como con el aprovechamiento de los recursos marinos.

A pesar de estos cambios, los pescadores camanchacas o camanchiangos continúan con un sistema de matrimonio endogámico, como lo demuestra el libro de Varias Ojas (Aldunate et al. 2010).

\section{El camino de Potosí, contrabandistas y viajeros (S. XVIII).}

Existe información elocuente sobre el contrabando existente entre Tarapacá y Atacama, que estaría en manos de población no indígena; según Cañete y Domínguez.

"Los pobladores de Pica y Tarapacá, que por lo regular son españoles, cholos o mestizos, se pasan a Atacama con mercaderías de la tierra, como son la coca, bayeta de la tierra, algunas cintas, cuentas y otras frioleras, para cambiarlas por trigo y maiz y también para el rescate de oro y plata; ellos vagan por todo el distrito engañando a los infelices indios...(Larrain 1974: 234)”.

El tráfico marino oficial de la plata de Potosí se hace por Arica, donde está la Aduana, que a través de las Cajas Reales controla el pago del tributo. Esto hace que Cobija, donde no hay autoridades coloniales ni controles administrativos, sea un punto apetecido para el contrabando y las recaladas de barcos extranjeros que burlan el estanco espańol.

Aprovechando el puerto, la lejanía de centros poblados y el abandono de las autoridades coloniales, Cobija se transforma en una recalada de contrabandistas europeos que embarcan plata de Potosí, eludiendo pagar el impuesto del quinto real. El siglo XVIII se caracteriza también por la llegada de viajeros y científicos europeos.

En general, Cobija, durante la época colonial, es considerada por las autoridades hispanas como un paisaje marginal, propicio para actividades informales. Por ello se densifica el tráfico del camino de Potosí a la costa (Figura 2); llegan viajeros y expediciones científicas, siendo las más conocidas las de Vincent Bauver (Bervau), francés, en 1707; Louis Feuillée, francés, en 1710; Amadée Frezier, francés, en 1730; Jorge Juan y Santa Cecilia, 
españoles, en 1735; Antonio de Ulloa, español, 1743, y Pedro Vicente Cañete y Domínguez, español, en 1789.

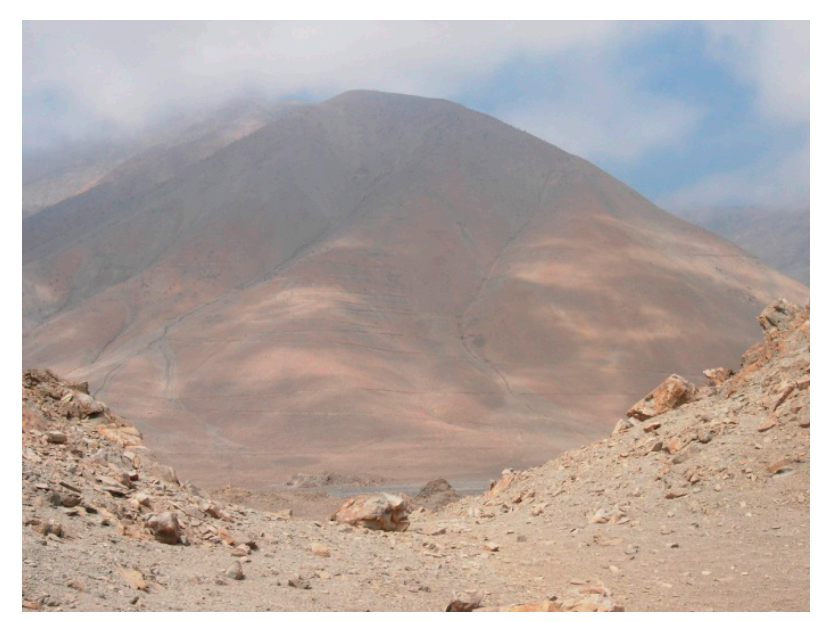

Figura 2: Camino de Cobija a Potosi.

Figure 2: Cobija to Potosi Road.

Para 1787 la población tributaria de Cobija era de 10 originarios, 9 cholos con tierras y un cholo sin tierras y ya en 1804, esta población había disminuido por lo menos a la mitad, lo que muestra una clara disminución de los tributarios. Una situación que demuestra abandono parcial del lugar y que los lugareños atribuían al abuso de los encomenderos sobre los arrieros (Hidalgo 1983:139- 140).

Calama es el punto nodal hacia el interior entre Cobija y las tierras altas:

La población que se le aporta menos es la de San Juan de Calama en distancia de treinta y nuebe leguas desproveidas de otro auxilio que no sea las leñas, y el yerbaje, para manutención de las bestias, y esto solo en los Parages de Guacate que se halla siete leguas mas adelante y en el de Chacame (sic) que corre de diez a once siguiendo el mismo Rio. De aqui hasta llegar al Puerto se ofrece una travesía de veinte y dos leguas con tan malos pasos, y Cuestas que a la salida ofrecen no poco afán a los Arrieros, con todo de que caminan la mayor parte de noche, y se valen de otras diligencias para auxiliar sus cabalgaduras (AGI Charcas 438. Carta No 156 del Gobernador Intendente de Potosí, Pino Manrique, Hidalgo 1983: 141). 


\section{Libertadores y gobernantes ilustrados de Bolivia (1815-1870)}

El siglo XIX es el que contiene la mayor cantidad de información y la mayor cantidad de cambios particularmente en cuanto al diseńo en el asentamiento y en las prácticas sociales y económicas que se desarrollan en Cobija.

Bolívar cifra en Cobija la esperanza de la naciente República y determina que es el único puerto que Bolivia puede ocupar para su vinculación con el mundo, en una época en que todas las comunicaciones a larga distancia eran marítimas. El gobierno hace enormes esfuerzos para el desarrollo de este puerto, a pesar de sus graves deficiencias. Las más grandes son su falta de agua y el estar separado de los centros bolivianos por cientos de kilómetros del desierto más árido del mundo y por serranías y salares inhóspitos, donde es muy difícil establecer postas para los caminos.

El cambio del paisaje es drástico tanto en su concepción, pues este territorio pasa a tener una importancia estratégica de primer nivel para la naciente república, cuanto a su expresión, pues se habilita y desarrolla una pequeña ciudad con todos sus servicios.

El 28 de diciembre de 1825 se reconoce la caleta como pueblo bajo el nombre de Lamar. En el decreto respectivo se funda el puerto mayor de Cobija o Lamar bajo el mandato y la firma del libertador Simón Bolívar (Arce 2004:16-17).

Sucre debió emprender el mejoramiento de Cobija; en mayo de 1826 le escribía a Bolívar:

El Puerto de la Mar (Cobija) se habilitará con mayor expectativa que beneficio... La adquisición de Arica es de suma importancia para Bolivia. Sería un magnifico puerto, especialmente con un buen camino a Cochabamba, pero si Perú lo retiene, podriamos declarar puerto libre a Cobija, que causaría la declinación de Arica (Fifer 1976: 54).

Así es como se pone énfasis en la habilitación de caminos y postas; se instalan el ejército, hospital, correo, aduana, etc., con sus respectivas construcciones, y se intensifica el tráfico terrestre y el marino.

De este modo, Cobija se transforma en el puerto de llegada de todas las mercaderías de ultramar enviadas a Bolivia y de zarpe de las exportaciones bolivianas, aunque se continuó utilizando a Arica, en el litoral peruano. Es el tiempo del auge del comercio marítimo boliviano. Se establecen varias casas comerciales que vinculan a Cobija con Potosí y La Paz (Bolivia), Valparaíso 
(Chile), y Salta y Jujuy en Argentina (Conti 2003). Las principales son Cotera, Artola, Tezanos - Pinto y Cía., Hnos. Latrille, la casa Durandeau, Dorado Hnos, etc. Al mismo tiempo, se inician las primeras labores mineras de importancia y una parte de los changos dedicados al mar, también se ocupan en faenas mineras.

Se instala una planta desalinizadora de agua de mar, condición necesaria para un asentamiento más permanente. Es el tiempo en que llega una gran cantidad de viajeros y científicos de paso hacia Perú, Potosí, La Paz, Salta y Jujuy, como por ejemplo, Francisco O'Connor, irlandés, en 1826, con la misión de buscar un puerto para Bolivia (González 1992); Jacques Antoine Moorenhout, francés, en 1828; William Bollaert, francés, en 1828; Alcides D’Órbigny, francés, en 1830; Rodolfo A. Philippi, alemán, en 1853-54; Johan J. Von Tschudi, austriaco, en 1858; León Palliére, francés, 1945; Herman Burmeister, alemán, en 1860; Manuel Almagro, español, en 1864, quien estando en Cobija, "se aprovisionó de los recursos necesarios para emprender la travesía del desierto de Atacama, en busca de objetos etnoarqueológicos" (González 1992: 21); y André Bresson, francés, 1870, entre otros.

No obstante este interés, la guerra de la Confederación Perú Boliviana, las invasiones peruanas a Cobija y la competencia de los puertos de Arica, Antofagasta y Valparaíso, sumadas a las desventajas naturales de esta localidad, conspiran contra el despegue de este puerto.

Las desoladas apreciaciones sobre Cobija por parte de los viajeros europeos, denotan la percepción de un paisaje muy diferente de aquel territorio lleno de posibilidades para los originarios cazadores recolectores marinos del territorio nortino. Un ejemplo: El paisaje de Cobija visto por A. D’Orbigny, en 1830:

Si el perfume de las flores y el aspecto grandioso de la hermosa vegetación del Brasil exaltó mi espiritu a mi llegada a Río de Janeiro, estuve muy lejos de experimentar las mismas emociones al recorrer con los ojos los campos de Cobija.

Me senti, por el contrario, profundamente entristecido, buscando inútilmente rastros de verdor. La naturaleza parecía estar de duelo, y lejos de hallar en esa tierra tan alabada del Perú, esa riqueza proverbial de aspecto, cuya idea despierta su nombre en todo el resto del mundo, veía a la derecha un cabo negro, formado de rocas desgarradas; frente, una costa donde el oleaje rompia con estrépito, en medio de rocas; algunas 
casas de pobre apariencia, al pie de la barranca cortada a pico; y, arriba, una llanura en pendiente completamente pelada, que parte del mar y se eleva poco a poco hacia las montañas abruptas y también secas y peladas. Todo el prestigio desapareció, y experimenté, no sin vivo detrimento de tristeza, el doble temor de no hallar nada pintoresco en esta tierra ingrata y ver defraudadas por completo mis esperanzas de descubrimientos. Sin embargo, reflexionando, al ver esa costa accidentada, esta vasta extensión marina, y arriba, rocas peladas, pensé que la zoología marina y la geología me ofrecian todavia tesoros y bastantes medios para llenar los momentos de descanso (D’Orbigny [1826-33] 2002: 1029-1030).

Y sin embargo, coexisten al menos varios paisajes culturales fuertes, entre otros: el del cazador recolector marino, que mira hacia el mar; el del navegante y viajero que percibe su calidad de puerto, la informalidad producto del abandono, y un paisaje, constituido por un diseño urbano, asentado en el lugar, que lucha por ser ciudad (Figura 3).

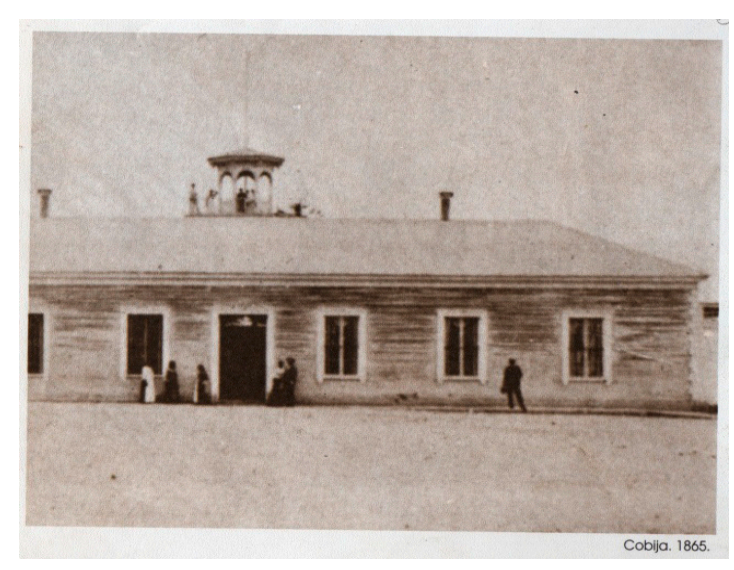

Figura 3: Cobija en 1865

Figure 3: Cobija in 1865

En 1829, el gobierno de Bolivia separa a Atacama de Potosí y nombra un prefecto en Cobija. Diez años después, Atacama es elevada a Departamento y dividida en dos provincias: Lamar (el litoral) y Atacama, con un prefecto en Cobija y un subprefecto en San Pedro de Atacama (García et al. 2000:66). Ello denota la aún creciente importancia de Cobija como puerto principal, al tiempo que replica el modelo jurisdiccional territorial que ya había implantado el poder eclesiástico en el siglo XVII. También significa la permanencia de una arquitectura de vivienda republicana 
temprana, para ser habitada por esta clase de funcionarios. Más tarde, hacia 1860, también se ha establecido un consulado de España en Cobija, con fines administrativos y comerciales (González 1992).

Un capítulo de la mayor significación que se expresa formalmente durante el XIX y es el eje articulador tierras altas - tierras bajas es la habilitación de caminos.

Después de la independencia de Bolivia, en 1825, cuando el puerto de Cobija se integró al comercio internacional, cobraron importancia antiguos caminos indígenas que conectaban el litoral Pacífico con el noroeste argentino, principalmente a través de la ruta que iba de Cobija, pasando por San Pedro de Atacama, hasta el noroeste argentino. De 1830 a 1860, período durante el cual los sectores mercantiles de Salta y Jujuy utilizaron al puerto de Cobija para su comercio de importaciones, se desarrolló la arriería como actividad relevante de los habitantes de oasis y valles de ambos lados de la cordillera. Las cargas se llevaban en asnos hasta Calama y de allí en mula hasta Salta o Potosí (Conti 2006).

En efecto, hemos comprobado en terreno, prospectando el camino entre Cobija y Calama (Castro et al. 2009), que uno de los marcadores del mismo, en el presente, son los esqueletos blanquecinos de mulares, que jalonan el camino en toda la extensión pampina. Por contraposición, en esta misma ruta no se hallan restos óseos de camélidos, demostración patente de la falta de agua para unos y la adaptación de otros.

Uno de los más graves problemas con los que tropezó Bolivia para la habilitación de Cobija fue su comunicación con el resto del país, problema que puede resumirse en pocas palabras: desierto, falta de agua y de pastos, falta de postas para el reposo de caminantes y de las arrías, cordillera, frío, cuestas, caminos llenos de tropiezos y un sinfín de otras condiciones. Hacia finales de la colonia se utilizaba la ruta Cobija-Chacance-GuacateCalama, Chiu Chiu-Santa Bárbara-Polapi-Tapaquilchas (se entra en Lipes). Viscachillas-Alota-Río Grande-Amachuma-Agua de Castilla-Porco-Potosí. En total, 177 leguas. Este camino no varió fundamentalmente en el período republicano (Flores et al. 2005). Igual que la habilitación del Puerto, la habilitación del camino se inició formalmente en 1827, durante el gobierno de Sucre; los periódicos invitan a viajar a Cobija, señalando itinerarios de Potosí a Cobija y de Oruro a Cobija (Cajías 1975: 65-66).

De acuerdo a los estudios previos y a los nuestros en terreno sobre el tramo Cobija - Calama (Castro et al. 2009), se hicieron enormes esfuerzos 
para mantener estos caminos y sus postas, pero las condiciones naturales, la escasez de agua y la aridez del desierto, siempre conspiraron en su contra; esta situación se asocia a la percepción de un paisaje yermo, árido, estéril, inhabitable.

Durante este siglo, Cobija sufre cambios significativos en su asentamiento, lo que se aprecia fuertemente en su diseño urbano. Un médico de la Armada de Estados Unidos, la describe en 1834:

Caminamos hacia la casa del gobernador que está frente al desembarcadero, y doblando a la izquierda nos encontramos con la calle principal y única de Cobija. Tendrá quizás un cuarto de milla de largo pero no está totalmente edificada. Las casas son todas de un piso y están construidas de madera y adobe, en el estilo más rudimentario posible, y muy pocas tienen patios. El revoque se prepara con agua salada (...). La madera que se trae de Chiloé y Concepción resulta en total más barata que el adobe (...) Una gran proporción de las casas está ocupada por tiendas, donde se exponen gran variedad de articulos extranjeros tanto americanos como europeos. El edificio más antiguo es una iglesia que se dice fue levantada hace ciento cincuenta años. Está construido de adobes de tamaño pequeño... un templo muy reducido y de humilde apariencia, abierto al mar por la única puerta que posee, que es doble y está asegurada por un candado común; en realidad, a menos que se llame la atención sobre ella, se podría creer que es un establo (Fifer 1976:60).

Es una época en que, a pesar de las condiciones precarias, hay optimismo por las inversiones que se han ido haciendo en Cobija y el Presidente Santa Cruz confía en 1834 en el éxito futuro de este puerto, destacando de este litoral, sus riquezas en cobre (Fifer 1976:62).

Pero la escasez del agua conspiraba siempre en contra. Los pozos eran salobres e insuficientes y en la época colonial se traía agua de Calama y San Pedro de Atacama. Las fuentes locales, en el costado del cerro, estaban cerradas bajo llave, dejando un angosto caño al exterior para llenar botellas (Fifer 1976:60-62). Hacia 1839, el gobierno boliviano seguía haciendo enormes esfuerzos monetarios destinando treinta mil dólares anuales para el fomento, pero todas la tentativas para un comercio estable se frustraban por la agotadora ruta de seiscientas millas entre el puerto y el altiplano. "Es un lugar siniestro, separado por un inmenso desierto de arena de la parte habitada del pais", observaba Masterton y "que en el mejor de los casos requiere por lo menos tres semanas de viaje hasta La Paz, en contraste con los siete u ocho días que insume el de Arica" (Fifer 1976: 71). 
A pesar de todas estas dificultades permanentes, Cobija tiene su época de oro para los comerciantes, en donde el diseño urbano y el tráfico marítimo y terrestre dan cuenta de un cambio radical a nivel productivo. Es la actividad del puerto de embarque, salida y llegada de bienes. Ello no debe hacernos olvidar que, en la cotidianidad, familias de changos siguen aportando a la alimentación diaria con su caza, recolección y pesca en la cordillera de la costa y en el litoral.

Personajes notables, como el fundador de Antofagasta, conocido como el "chango López", que en realidad fue un esforzado industrial minero residente de La Chimba, entonces caleta y hoy parte de Antofagasta, viajaban continuamente a Cobija para abastecerse de víveres frescos y de operarios. Extraía metales cerca de Antofagasta, los que despachaba en su gran bote, El Halcón, hacia el puerto (Arce 2004: 50). En realidad todo se operaba en Cobija, porque todo llegaba y todo salía de este nodo, en aparente contradicción con su denotada desolación. Era el centro urbano administrativo de todo el litoral regional y el único nexo con las tierras altas de ambas vertientes de la cordillera de los Andes en Atacama.

Hacia 1840, hay explotación de minas en toda la franja costera y en el interior. El mineral extraído de esos lugares es transportado en carretas (Figura 4) a la fundición instalada en Cobija (Flores et al. 2005: 96). Aún en pleno siglo XXI, encontramos las huellas de las ruedas sobre la arena terrosa del litoral y en el camino de la pampa (Castro et al. 2009).

Con una población mestiza y extranjera, la iglesia revitaliza la Parroquia de Santa María Magdalena de Cobija, que atendía a toda la población del litoral entre el río Loa hasta el paralelo $24^{\circ}$ (Figura 5). También se asienta casa parroquial en la localidad (Flores et al. 2005: 117-121). Hacia 1862, se habían fundado dos escuelas en Cobija (Arce 2004: 69), acorde con el plan no solo económico sino también político, social y cultural para la población del puerto y del litoral a nivel regional. También se había reorganizado el servicio de Aduanas. El 30 de octubre de 1871, desde Sucre, el Ministerio de Relaciones Exteriores comunicaba:

Al Señor Prefecto del Departamento de Cobija. Señor: En protección al desarrollo económico y social del Departamento litoral de Cobija, al estado excepcional en que se encuentra y en atención a su naciente población, compuesta en su mayor parte por inmigrantes extranjeros, S.E. Presidente de la República ha resuelto: Que pueden los extranjeros domiciliados en ese Departamento por más de un año, y establecidos con alguna industria o profesión, desempeñar los cargos concejiles que se necesitaren para servir los 
intereses de cada localidad, teniendo libre ejercicio de su culto las colonias que se estableciesen en las poblaciones de nueva creación... (Arce 2004: 114).

Es recién en el último tercio del siglo XIX, cuando Cobija empezará a ser paulatinamente reemplazada por Antofagasta como puerto principal, entre otras cosas porque entre 1860 y 1870 se descubren guaneras, salitre y nuevas minas y la provincia boliviana de Atacama se convierte en un distrito más significativo comercialmente. Justamente, la ciudad puerto de Antofagasta es fundada el 22 de octubre de 1868 (Flores et al. 2005: 69). Bolivia crea una nueva subprefectura en Caracoles y la capital pasa de Cobija al puerto de Antofagasta (García et al. 2000: 67).

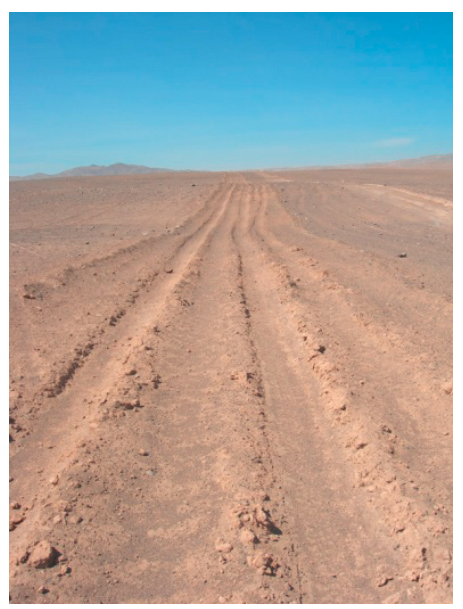

Figura 4: Camino de Carretas en Guasilla al sur de Cobija

Figure 4: Heavy cart road from Guasilla to south of Cobija

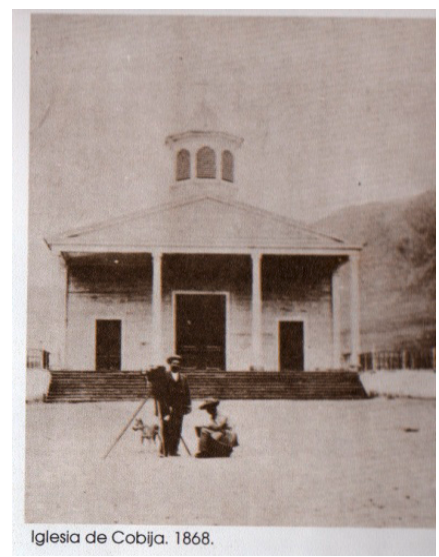

Figura 5: Iglesia de Cobija. 1876

Figure 5: Cobija's church, 1876 
Los desastres de la naturaleza, la peste y la guerra (1868-1880).

El 14 de febrero de 1879, encontró a Bolivia sin defensa frente a los 600 soldados chilenos que llegaron a Antofagasta. Abaroa defendía Calama mientras la flota chilena tomaba Cobija y Tocopilla (Fifer 1976: 94). Cobija había sido azotada por terremotos y maremotos que la dejaron en ruinas (Figura 6).

En pleno desarrollo industrial por los años 1870, el puerto sufrió tremendos embates de la naturaleza. Dos terremotos seguidos de dos maremotos igualmente devastadores y una peste de fiebre amarilla, terminan con las instalaciones urbanas y portuarias de Cobija y diezman a su población. Acto seguido, la Guerra del Pacífico, entre 1879 y 1880 anexa estos territorios a la República de Chile. Sus causas fueron las riquezas mineras de esta región, sobre todo el salitre, que amparaban fuertes intereses extranjeros.

Los terremotos y maremotos fueron el 13 de agosto de 1868 y el 8 de mayo de 1877. La epidemia de fiebre amarilla en 1869, fue de tal magnitud que dejó al pueblo casi deshabitado. Viudas y huérfanos quedaron desamparados. Sin embargo, hacia 1870, vuelve paulatinamente a repoblarse e incluso se funda un Banco para facilitar las operaciones mercantiles: el "Banco Nacional de Bolivia”. Su consejo general de administración se radicó en Valparaíso, teniendo como presidente a Don Agustín Edwards Ross (Arce 2004: 94). En este año también se descubre la mina de plata de Caracoles, que acrecienta la gente interesada en su explotación. El tráfico entre la costa y el mineral se hacía en su mayor parte por Cobija, desde cuyo puerto había una distancia de 63 leguas. La ruta iba de "Cobija a Culupo, 13 leguas; de Gulupo a Miscanti, 15 leguas; de Miscanti a Calama, 17 leguas; de Calama a Caracoles, 18 leguas" (Arce 2004: 98-99). 


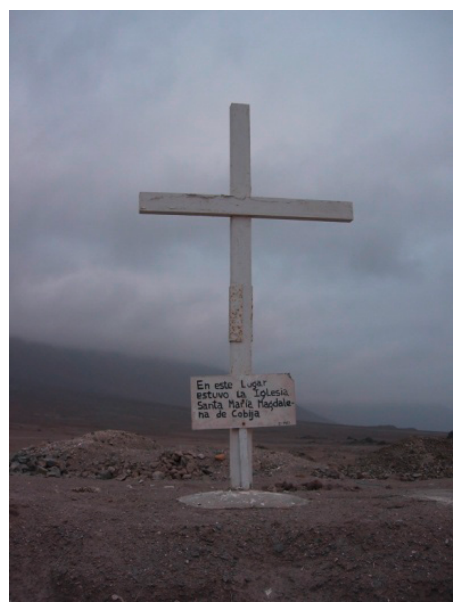

Figura 6: En este lugar estuvo la Iglesia de Cobija

Figure 6: In this place was the church of Cobija

De particular intensidad fue el terremoto y maremoto de 1877 para Cobija. Se derrumbaron la mayor parte de los edificios y luego el mar arrasó con familias completas (Arce 2004: 357). El paisaje relicto que hoy puede observarse en Cobija comprende estas ruinas de adobe, de alturas aún imponentes, de las que queda uno que otro muro (Figura 7). En la superficie, los efectos de los maremotos son evidentes. Nunca más se reedificó y la desolación se siente hasta hoy, no obstante la belleza escénica del lugar.

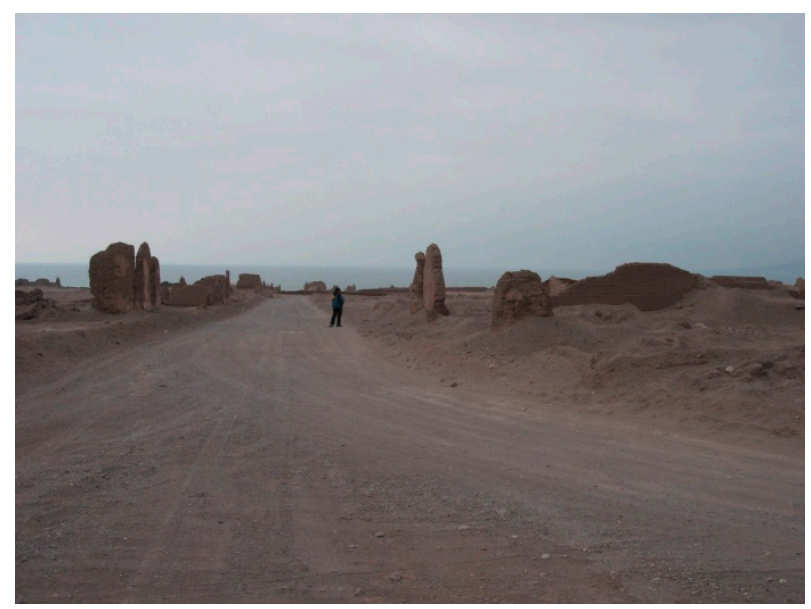

Figura 7: Calle principal de Cobija, llamada El Beni Figure 7: Main street from Cobija, named El Beni 


\section{El paisaje Chango SObReVive (I88o - hasta El PRESENTE).}

En medio de las ruinas, Cobija vuelve a ser el escenario que albergó a los cazadores, pescadores y recolectores marinos, en todos los tiempos de su historia, desde sus primeros asentamientos humanos. En el presente, el antiguo puerto y muelle de Cobija han desaparecido y sólo queda un pequeño muelle para la pesca.

Habitan unas 26 familias de pescadores - recolectores en un lugar que ha sido declarado Monumento Nacional por el Estado de Chile, coexistiendo con las ruinas de un pasado que no obstante enormes dificultades, en una época transformó una sencilla caleta changa en una ciudad y que, luego de los desastres, volvió a ser una caleta de pescadores. Pero los changos, probablemente desde la época precolombina, también son mineros ocasionales, aunque la mayor visibilidad de esta combinación de changominero se da sin duda en el siglo XX y en las coyunturas del siglo XXI.

El paisaje de Cobija del cual son parte los actuales changos es un ámbito de vida y de trabajo (Figura 8). Viven de frente al mar, inmersos en su quehacer, pero a corta distancia de dos ciudades, Tocopilla y Antofagasta, conectados por una moderna carretera aledańa al pueblo. En consecuencia, para ellos, el paisaje no sólo incluye el mar como recurso de subsistencia tradicional, sino también la ciudad con la que se conectan a través del mercado para la venta y comercialización de sus recursos y para los placeres urbanos (véase Escobar 2007). Para los modernos changos el paisaje también se ha ampliado con la tecnología, a través de la pesca submarina.

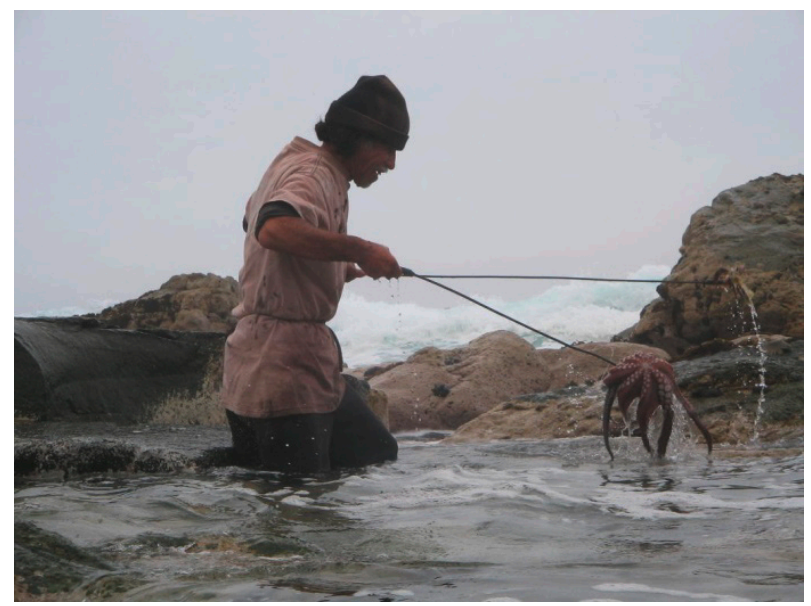

Figura 8: Don Manuel, cazador recolector contemporáneo en Cobija (foto de M. Escobar, 2005). Figure 8: Mister Manuel, contemporary hunter-gatherer in Cobija (Photo taken by M. Escobar, 2005). 
Ellos visualizan análogas categorías geomorfológicas del paisaje terrestre, que se encuentran bajo el mar. Describen cerros de hasta 90 metros, "playones" y "bajerías", donde se cobijan las especies marinas que pescan y recolectan; este tipo de conocimiento y su profundo saber sobre las especies que pescan y recolectan los remite más bien a un paisaje cobijano de carácter asociativo. Con las ruinas, las pocas familias que aún habitan permanentemente en Cobija tienen percepciones negativas y positivas. Para algunos es la historia y merece cuidarse y protegerse. Para otros, es una traba al progreso y la modernidad. Irremediablemente ambos grupos coexisten con el paisaje relicto y la belleza escénica de su litoral.

En términos generales, tras cuatro siglos de historia, Cobija vuelve a ser el paisaje pródigo para pescadores y recolectores marinos que siempre fue.

Agradecimientos: A los proyectos de Investigación, FONDECYT 1050991 que inauguró nuestros estudios en la zona, y FONDECYT 1100951 que nos permite continuarlos. A los pobladores de Cobija. A dońa Fresia Jaug por su cobijo en Cobija, a los evaluadores del manuscrito y al editor de la Revista, por sus cuidadosas observaciones.

\section{BiBLIOGRAFÍA}

Aldunate, C.; V. Castro y V. Varela. 2010. "Los atacamas y el Pescado de Cobija. En homenaje al Maestro John Víctor Murra”. Chungara, 42(1):341-347

Andrade P. 2011. "Informe Bioarqueológico del Individuo 1 del sitio Copaca 1. Provincia de Tocopilla, II Región de Antofagasta". Informe Año 1, FONDECYT 1100951. Manuscrito en posesión del autor.

Andrade P. 2012. "Informe Bioarqueológico del individuo 2 y 3 del sitio Copaca 1. Provincia de Tocopilla, II Región de Antofagasta". Informe Año 2, FONDECYT 1100951. Manuscrito en posesión del autor.

Arce, I. 2004. Narraciones Históricas de Antofagasta. Corporación Pro Antofagasta, Antofagasta.

Berenguer, J. 2008. "Naves prehispánicas en el mar de los Changos". En Pescadores de la niebla. Los changos y sus ancestros, editado por L. Cornejo, pp: 31-40. Museo Chileno de Arte Precolombino, Santiago.

----- 2009. "Las pinturas del Médano, Norte de Chile: 25 años después de Mostny y Niemeyer". Boletin del Museo Chileno de Arte Precolombino 14 (2): 57-95. 
Bibar, J. de. [1558]1966. Crónica y Relación Copiosa y Verdadera de los Reinos de Chile. Fondo Histórico y Bibliográfico José Toribio Medina, Santiago.

Bittmann, B. 1979. "Cobija y sus alrededores en la época colonial (1600-1750)". Actas del VII Congreso de Arqueología Chilena, tomo II, pp: 323-326. Altos de Vilches, Chile.

---- 1980. "Proyecto de investigación interdisciplinaria en la Costa Centro-Sur Andina”. En Proyecto de Investigación Interdisciplinaria en la Costa CentroSur Andina, editado por B. Bittmann, M. T. Ahumada y C. Moragas, vol I, pp: 11- 20. Universidad del Norte, Sede Antofagasta, Departamento de Arqueología. Imprenta Universitaria, Antofagasta.

----- 1983. "Cobija: panorama etnohistórico en relación a los informes del Dr. José Agustín Arze”. Chungara,10: 147-153.

----- 1984. "El proyecto Cobija: Investigaciones Antropológicas en la costa del desierto de Atacama (Chile)". Actas del XLIV Congreso Internacional de Americanistas, pp: 99-146. San Pedro de Atacama, Chile.

----- 1986. "Recursos Naturales renovables de la costa norte de Chile: Modos de obtención y uso". En Etnografía e historia del mundo andino. Continuidady cambio, editado por S. Mazuda, pp: 269-334. Universidad de Tokio, Tokio.

Cajías, F. 1975. La Provincia de Atacama. 1825 - 1842. Instituto Boliviano de Cultura, La Paz.

Castiglioni, B. 2007. L'ipertesto Paesaggio: Un Esempio per i Colli Berici. Universitá di Padova, Italia.

Cases, B.; Ch. Rees, G. Pimentel, R. Labarca y D. Leiva. 2008. "Sugerencias desde un contexto funerario en un "espacio vacío" del desierto de Atacama". Boletín del Museo Chileno de Arte Precolombino 13(1): 51-70.

Castro, V. 1997. Huacca Muchay. Evangelización y Religión Andina en Charcas, Atacama La Baja. Tesis para optar al grado de Magíster en Ciencias Históricas, Mención Etnohistoria. Departamento de Ciencias Históricas, Facultad de Filosofía y Humanidades, Universidad de Chile.

----- "Sabores ancestrales. Caza, recolección y producción de alimentos en el norte prehispánico". En Historia de la alimentación en Chile, un enfoque multidisciplinario, editado por C. Schiolla, pp: 27-85. Catalonia, Santiago.

Castro, V.; C. Aldunate y V. Varela. 2011. Informe de avance $1^{\circ}$ año FONDECYT 1050991. Manuscrito en posesión del autor.

2009. Informe final FONDECYT 1050991. Manuscrito en posesión del autor. 
Conti, V. 2003. "Estrategias mercantiles, redes y migraciones de comerciantes durante el período rosista". Cuadernos de la Facultad de Humanidades y Ciencias Sociales 21:59-73.

----- 2006. "La ruta de los arrieros y el salitre". En Las rutas del Capricornio Andino, editado por A. Cabeza, M. I. Hernández, L. Núñez y M. Vásquez, pp: 93-104. Consejo de Monumentos Nacionales, Santiago.

Cruz, B. y L. Bravo. 1980. "Cobija Sur 1; sitio de ocupación temprana en la costa de Cobija, II Región, Chile". En Cobija: proyecto de investigaciones interdisciplinarias en la costa Centro sur andina (Chile), editado por B. Bittmann, M.T. Ahumada y C. Moragas, vol. 1, pp: 153-173. Departamento de Arqueología, Universidad del Norte, Sede Antofagasta. Imprenta Universitaria, Antofagasta.

De Saussure F. 1945. Curso de Lingüistica General. Editorial Losada, Buenos Aires.

Devora, E. M. 2006. "Aproximaciones a la noción de paisaje en las culturas andinas de la América”. Complexus Revista de Complejidad, Ciencia y Estética 2(1): $58-90$.

D’Orbigny, A. [1826-33] 2002. Viaje a la América Meridional, Tomo III. IFEA, La Paz.

Escobar, M. 2007. Orillero en Cobija. Cazador Recolector Contemporáneo del Desierto Costero. Memoria para optar al título de Antropólogo social, Departamento de Antropología, Facultad de Ciencias Sociales, Universidad de Chile, Santiago.

Fifer, V. 1976. Bolivia. Editorial Francisco de Aguirre, Buenos Aires.

Flores, N.; J. Rivera y F. Rivera. 2005. El ayer de Cobija y Gatico. Presencia de la Iglesia Católica. Universidad Católica del Norte, Ediciones Universitarias, Antofagasta.

García, S.; D. Rolandi y D. Olivera. 2000. Puna e Historia. Antofagasta de la Sierra, Catamarca. Asociación Amigos del Instituto Nacional de Antropología, Buenos Aires.

González, J. A. 1992. La Comisión Cientifica Española al Pacifico en Chile (18621865). Diario de Francisco Martínez y Sáez. Ediciones Universitarias, Universidad Católica del Norte, Antofagasta.

Hidalgo, J. 1983. "Dos documentos inéditos y un mapa de Cobija: informes del comisionado Dr. José Agustín Arze, 1786-1787”. Chungara 10: 139-146. 
Ingold, T. 1996. "Hunting and gathering as ways of perceiving the environment". En Redefining nature, editado por R. Ellen y K. Fukui, pp: 117 - 155. Berg, Oxford.

Larraín, H. 1974. "Documento $n^{\circ}$ 1. Proyecto previo en que se demuestra la conveniencia que debe esperarse a beneficio del Rey y del Estado, si se agrega al virreinato de Buenos Aires el Partido de Tarapacá, con el cerro rico de Guantajaia y su territorio, tirando la línea de demarcación por la quebrada de Camarones. Pedro Vicente Cañete y Domínguez, con notas y bibliografía de H. Larraín”. Norte Grande I (2): 233-242

Lizárraga, R. de [1594-1608] 1987. "Descripción del Perú, Tucumán, Rio de la Plata y Chile. Editado por I. Ballesteros. Historia 16, Madrid.

Llagostera, A. 1977. "Ocupación humana en la costa norte de Chile asociada a peces local - extintos y a litos geométricos: 9680 +- 160 A.P”. Actas del VII Congreso de Arqueología Chilena, tomo I, pp: 93-113. Sociedad Chilena de Arqueología, Santiago.

----- 1982 "Tres dimensiones en la conquista prehistórica del mar: Un aporte para el estudio de las formaciones pescadoras de la costa surandina". Actas del VIII Congreso Nacional de Arqueología Chilena: 217-245. Kultrún, Santiago.

----- 1990. "La navegación prehispánica en el norte de Chile. Bioindicadores e inferencias teóricas". Chungara 24/25: 37-51.

Latcham, R. 1938. Arqueología de la Región Atacameña. Prensas de la Universidad de Chile, Santiago.

Lozano de Machuca, P. [1581] 1885. "Carta del Factor de Potosí Juan Lozano de Machuca al virrey del Perú, en donde describe la provincia de los Lipes, de diciembre de 1581". En Relaciones Geográficas de Indias, editado por M. Jiménez de la Espada, Tomo II, Apéndice III, pp: xxi- xxviii. Ediciones Atlas, Madrid.

Lucero, M. 2008. "Ecofactos y Artefactos conquilógicos de Cobija 1 Norte". Informe de avance $1^{\circ}$ año FONDECYT 1050991. Manuscrito en posesión del autor.

Maldonado, A. 2006. "Informe colecta de Flora Sector Cobija y alrededores, II Región". Informe de avance $1^{\circ}$ año FONDECYT 1050991. Manuscrito en posesión del autor.

Martínez, J.L. 1996. "Papeles distantes, palabras quebradas. Las informaciones sobre Lipes en el siglo XVI". En La interacción surandina cinco siglos después. Compilado por: Albó, M. Arratia, J. L. Núñez, A. Llagostera, M. Isabel Remy y Revesz. Estudios y Debates Regionales Andinos 91: 229-260. 
Matienzo, J. de [1567] 1910. Gobierno del Perú. Compañía Sudamericana de Billetes de Banco, Buenos Aires.

Moragas, C. 1982. "Túmulos funerarios en la costa sur de Tocopilla (Cobija) - II Región (Chile)”. Chungara, 9: 152-173.

Mostny, G. y H. Niemeyer. 1983. Arte Rupestre Chileno. Serie El Patrimonio Cultural Chileno, Departamento de Extensión Cultural del Ministerio de Educación, Santiago.

Munizaga, J. 1980. "Restos óseos humanos de la costa norte de Chile (Análisis de cementerios disturbados de Cobija, II Región, Chile”. En Proyecto de investigación interdisciplinaria en la costa centro-sur andina, editado por B. Bittmann, M. T. Ahumada y C. Moragas, vol I, pp: 199-216. Universidad del Norte, Sede Antofagasta, Departamento de Arqueología. Imprenta Universitaria, Antofagasta.

Niemeyer, H. 2010. Crónica de un descubrimiento. Las Pinturas rupestres del Médano, Taltal, Editado por F. Gallardo. Museo Chileno de Arte Precolombino, Santiago.

Núnez, L. 1984. Tráfico de Complementariedad de Recursos entre las Tierras Altas y el Pacífico en el área Centro sur Andina. Tesis para obtener el grado de Doctor, Departamento de Antropología Cultural, Universidad de Tokio, Tokio.

-----1996. "Movilidad caravánica en el área centro sur andina: Reflexiones y expectativas". En La interacción surandina cinco siglos después, compilado por X. Albó, M. Arratia, J. Hidalgo, L. Núñez, A. Llagostera, M. Remy y B. Revesz, pp: 43-62. Centro de Estudios Regionales Andinos Bartolomé de Las Casas, Cusco.

Núñez, P. y R. Contreras. 2008. "El arte rupestre de Taltal, Norte de Chile". Taltalia 1: 77-85.

Pimentel, G., Ch. Rees, P. De Souza y P. Ayala. 2010. "Estrategias de movilidad del periodo formativo en la depresión intermedia, Desierto de Atacama". Actas del XVII Congreso de Arqueología, tomo II, pp: 1353- 1364. Valdivia, Chile.

Polo de Ondegardo, J. [1571] 1916. Informaciones acerca de la Religión y Gobierno de los Incas. Edición de Horacio Urteaga y Carlos Romero. Colección de Libros y documentos referentes a la historia del Perú, primera serie Tomo III, Lima.

Ruz, J. 2011. "Análisis ictioarqueológico del sitio Pta. Guasilla 2". Informe de Avance año 1. FONDECYT 1100951. Manuscrito en posesión del autor. 
Salazar, D.; V. Castro, H. Salinas y V. Varela. 2009. "Nuevas investigaciones sobre la prehistoria y la antigua minería de Taltal”. Taltalia 2: 111-118.

Santa Cruz Pachacuti Yamque, J. [1608] 1968. Relación de Antigüedades deste Reyno del Perú. Tomo 209. B.A.E., Madrid.

Torres, C.; W. Pestle y F. Gallardo. 2012. "Eating Fish in the Driest Desert in the World: Osteological and Biogeochemical Analyses of Human Skeletal Remains from the San Salvador Cemetery, North Chile". Latin American Antiquity 23 (1): 51-69.

Torres, J. 2008. "Estudio de los restos ictioarqueológicos de los sitios Cobija 1 Norte y Cobija 24". Informe de avance $1^{\circ}$ año FONDECYT 1050991. Manuscrito en posesión del autor.

Varela, V. 2009. "La cerámica Arqueológica de Taltal”. Taltalia 2: 119-128.

Vásquez de Espinoza, A. [1630]1948. Compendio y Descripción de las Indias Occidentales Smithsonian Institution, Washington.

Zanolli, C. 2005. Tierra, Encomienda e Identidad: Omaguaca (1540-1638). Sociedad Argentina de Antropología, Altuna Impresores S.R.L, Buenos Aires. 